globes from the library of the Inner Temple, made in the time of Queen Elizabeth.

There are about 200 atlases shown, like the wall-maps, from various countries-England, Germany, France, Austria, Belgium, Holland, Italy, Switzerland, Denmark, Sweden. Even more than in the wall-maps does the superiority of Continental work to English work come out in these publications. Many of these cheap foreign schoolatlases contain some of the finest cartographical work: such as Wettstein's atlas, published in Zürich for about half-a-crown, with about thirty maps of perfect finish. In this, as in some other foreign atlases, are one or two sheets intended to give the pupil an elementary idea of the principal symbols used in cartography--notably of hill-shading. With such a knowledge the pupil will see far more in a really good map than otherwise he could possibly see. Accuracy, beauty, and adaptability to their special purposes are far more frequent characteristics of Continental school-atlases and wall-maps than of English.

Of text-books there are some two or three hundred from all the countries already named, including a few from America. The vice of English text-books is the prominence given to mere memory-work, and the absence of any attempt to show the relations between physical and political geography. Of physical geographies and physiographies we have a few that are not surpassed by those of any country. It is the general text-book that is put together with so little skill and knowledge. In this departmen: foreign countries show far more unsatisfactory work than in the case of maps. Some of the best Continental text-books, especially German, are small, such as that of Kirchhoff, used in all classes of German schools, and in which mere memory-work is reduced to a minimum. In Germany, and indeed in most of the Continental countries represented, the teacher is of far more importance than the text-book, and is to a large extent independent of it ; in England everything must be put into the text-book, for few of our teachers know anything of the subject. It is a mistake altogether to write text-books for the youngest classes, those in which elementary notions and local geography are taught; these should depend entirely on the living voice of the teacher, with black-board, compass, simple reliefs, and pictures.

Such are a few of the exhibits brought together in this very useful Exhibition; there can be no doubt that the many teachers who have visited it will have learned a few useful lessons; we hope, for one thing, they will be more exacting as to the character of the maps and other appliances supplied by publishers.

A series of lectures has been arranged in connection with the Exhibition, which so far have been well attended, and been followed by useful discussions. In December two lectures were given, one on the aims and methods of geographical education, the other on appliances. Last Tuesday Mr. Bryce lectured on the historical bearings of geographical education, and next Tuesday Prof. Moseley lectures on its scientific bearings, with Sir Joseph Hooker in the chair. On Saturday next a Conference will be held, in which the whole subject of the position of geographical education will be discussed, with special reference to its place in examinations; Sir Beauchamp Walker, ex-Director of Military Education, will preside at the Conference.

\section{HUNTER'S HOUSE}

THE three subjoined drawings are very faithful delineations of some of the portions of John Hunter's house and grounds, at Earl's Court, to which I drew attention in NATURE for Jan. 7. The first drawing supplies the view of the house looking into the meadow, in which view the house is, I believe, nearly the same as it was when Hunter lived in it. The second sketch is that of the Lions' House, or den, situated at the end of the
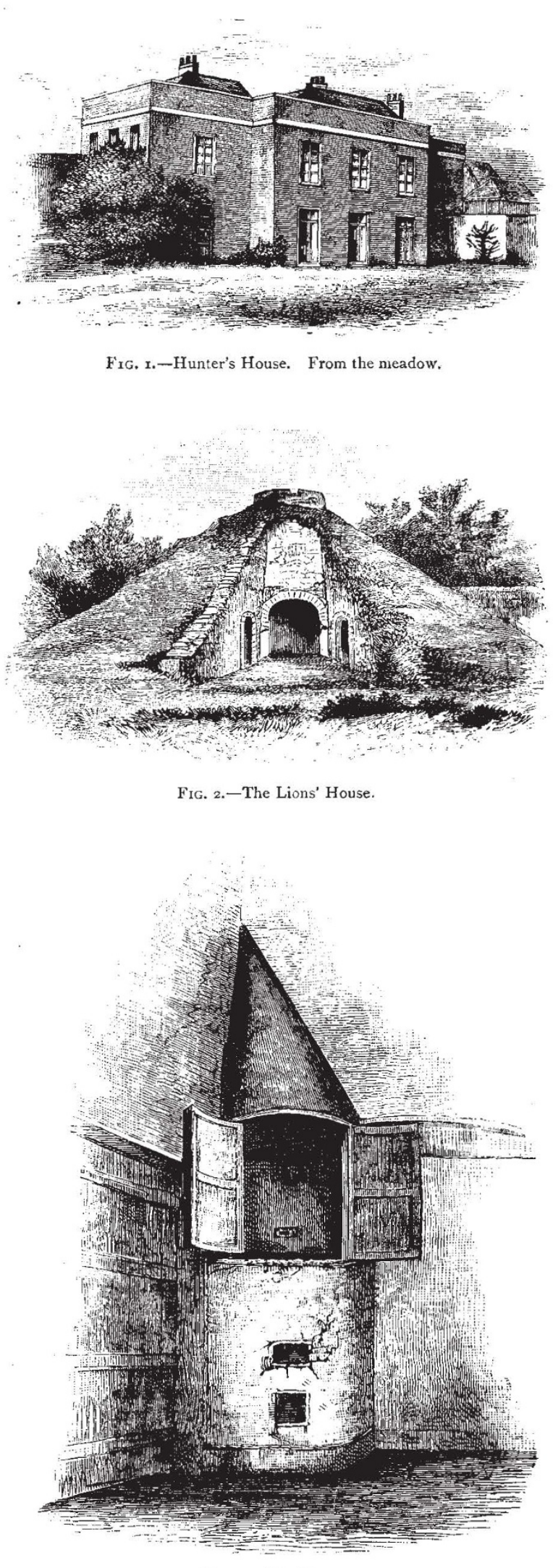

Fig. 3.-The Copper. 
meadow at the back and to the right of the house, but quite visible from the windows. The Lions' House, as will be seen, is a raised mound of earth. The earth rests upon an arched structure, which, at the time of my last visit, was in excellent condition, although ever since Hunter's time it has been a cow-house, and has done nearly a century of useful service. At the top of the mound there is a little wall, of a circular shape, inclosing a small open space. The third sketch illustrates the famous copper in which the Irish giant was boiled to a skeleton. The space above the copper up to the flue from the roof is covered in, but two doors open in front above the mouth of the copper. The whole of this structure has remained in good preservation.

The sketches are selected for NATURE from views which Bertram Richardson has taken during the last autumn, as part of a series of homes and birthplaces of illustrious men.

B. W. RICHARDSON

THE METEOR SHOWER AT THE MAURITIUS

$\mathrm{N}^{\mathrm{N}}$ the evening of Friday, the 27 th of November last, a great shower of meteors was observed at Mauritius.

The weather was cloudy and the sky often overcast, but from the accounts which I have received from different parts of the island it would appear that the shower lasted from at least 7 p.m. till midnight.

At Reduit, about 900 feet above the sea-level, where the sky was clearer than at the Observatory, His Excellency Sir J. Pope Hennessey, saw many bright meteors, which at first appeared to travel from N.W. to S.W., and a crackling noise was heard.

Looking on from 8 to 8.30 p.m. at Beat Bassin, Col. Stewart, R.E., saw about twenty meteors per minute, apparently travelling from N.W. to S.W.

About 7 p.m. several members of the Rev. Mr. McIrvine's family, happening to turn their faces towards the north, immediately observed a number of bright meteors, and in a short time they counted 200. Later on, Mr. McIrvine and two other observers counted 700 in three-quarters of an hour, although the sky was much overcast to the west and north and slightly to the east. Between 8.45 and 9 p.m. Mr. McIrvine and Mr. Hollway counted I 50 passing along a narrow clear space just above Orion. From 9 till midnight the sky was several times quite overcast, and as the clouds cleared away the meteors could be seen faintly through the mist, gliding along ghost-like. Between II.34 and II.5O Mr. McIrvine counted 160, which appeared in an unclouded space between Orion and the zenith. The sky was clouded towards the north the whole evening, and the meteors seemed to come from under that cloud, and, with few exceptions, they all travelled towards the south. Occasionally, a small one, needle-like, darted now towards the S.E., now towards the S.W., but none were seen going back, or even so far aside as east or west. Most of the meteors were small and needle-like, of a whitish colour, with paths extending from $5^{\circ}$ to $40^{\circ}$, although some seemed to appear and vanish instantly without perceptible movement. The meteors moved quickly, not unlike arrows approaching the target in an archery competition. The very largest travelled slowly across $30^{\circ}$ to $50^{\circ}$, and some of them were blue, some white, some red. Many of them looked like comets, and every now and then it was noticed that the head-which was very distinct-suddenly vanished, while the double-winged train $\left(20^{\circ}\right.$ to $40^{\circ}$, or more, in length) still moved on.

At Vacoas, at an altitude of nearly 1300 feet, the Hon. Mr. Elliott first saw the meteors at 7.15, and he counted 79I from 8.35 to 9.15 . The principal direction seemed to be from N.N.E. to S.S.W. The most brilliant passed near Venus.

In the same part of the island, Mr. Freeland observed a great many meteors between 10.15 and II.30. The shower was not constant, but at short intervals, and the meteors travelled from north to south.

At the Observatory, in the northern part of the island, the weather was cloudy, and the sky generally entirely overcast. At 8.20 p.m. several meteors were seen coming from the northward. Between 9.I and 9.9 Mr. Bell and myself, with two other observers, counted not less than 204, though the greater part of the sky was overcast, and not less than 173 between 9.9 and 9.16. Between 9.26 and 10.40, the sky was completely overcast. From 10.40 to 10.50 glimpses of Aries, Taurus, and Orion were got, and in that interval six large meteors with long trains passed towards the south-eastward between $\alpha$ Arietis and the Pleiades, and three more between 0.30 and $0.40 \mathrm{a} . \mathrm{m}$. The sky then began to clear up towards the N.W. and north, and I kept up watch till I.I 5 a.m., but no more meteors were seen.

I did not see the similar shower that was observed here in 1872 ; but from what I saw between 9.1 and 9.16 p.m on the 27 th of November last, during which time Andromeda, Aries, Taurus, Orion, \&c., were visible, it is certain that the radiant-point was near $\gamma$ Andromedæ, or that there was a radiant-space around that star.

The meteors shot to the southward, south-eastward, and south-westward, some of the largest with trains of $20^{\circ}$ to $40^{\circ}$ in length, disappearing to the southward behind the Port Louis and Pieterboth mountains, and others bursting with great brilliancy near Venus, Fomalhaut, $a$ Gruis, \&c.

On referring to the account given of the shower of November 27,1872 , by Mr. C. Bruce and Mr. Ed. Newton, it would appear that the radiant-point was the same on both occasions, or very nearly so, but that the maximum intensity of the shower was earlier this year than in 1872 .

Mauritius, December 22, 1885

C. MELDRUM

\section{NOTES}

THE meeting of the British Association to be held at Birmingham, beginning on Wednesday, September $\mathrm{I}$, will derive more than usual interest and importance from the exhibition of local manufactures which is to be held in connection with it. The Exhibition will be on a very much larger scale and of a much more popular and attractive character than has ever been attempted before. It is to be an Exhibition illustrative of products and processes connected with the manufacturing districts of Birmingham and the surrounding district within a radius of fifteen miles, which will include the whole of the Black Country, the nail district, and other towns where manufactures are carried on. The Exhibition will be on a very complete scale, and will embrace as nearly as possible all the industries of the district, which will include the following:--Engineering, hardware, heating and lighting, arms and ammunition, jewelry, glass and pottery, stationery, leather, furniture and decoration, and a miscellaneous class, including scientific and musical instruments. The special feature of the undertaking will be that in every tracle represented processes will be either completely shown or fully indicated. Workmen will be seen engaged in carrying out most interesting or difficult operations connected with various industries. The Exhibition will be opened on August 26, and close on October $\mathbf{I}$, three weeks after the termination of the visit of the Association.

A PROJECT has been started in Berlin to establish there an Anthropological Exhibition, which will do with regard to the races of men what zoological gardens do with regard to animals. In the Exhibition or garden it is intended that representatives of various races shall permanently reside, while of such races as cannot stand the cold of the climate representatives will be brought to Germany to reside there during the summer. An 